\title{
Rheological and mechanical properties of acellular and cell-laden methacrylated gellan gum hydrogels
}

\author{
Joana Silva-Correia, ${ }^{1,2}$ Antonio Gloria, ${ }^{3}$ Mariana B. Oliveira, ${ }^{1,2}$ João F. Mano, ${ }^{1,2}$ \\ Joaquim M. Oliveira, ${ }^{1,2}$ Luigi Ambrosio, ${ }^{3}$ Rui L. Reis ${ }^{1,2}$ \\ '3B's Research Group-Biomaterials, Biodegradables and Biomimetics, Department of Polymer Engineering, University of \\ Minho, Headquarters of the European Institute of Excellence on Tissue Engineering and Regenerative Medicine, AvePark, \\ S. Cláudio de Barco, Caldas das Taipas, Guimarães, Portugal \\ ${ }^{2}$ ICVS/3B's—PT Government Associate Laboratory, Braga/Guimarães, Portugal \\ ${ }^{3}$ Institute of Composite and Biomedical Materials, National Research Council of Italy, P.le Tecchio 80, 80125 Naples, Italy
}

Received 27 November 2012; revised 30 January 2013; accepted 4 February 2013

Published online in Wiley Online Library (wileyonlinelibrary.com). DOI: 10.1002/jbm.a.34650

\begin{abstract}
Tissue engineered hydrogels hold great potential as nucleus pulposus substitutes (NP), as they promote intervertebral disc (IVD) regeneration and re-establish its original function. But, the key to their success in future clinical applications greatly depends on its ability to replicate the native 3D micro-environment and circumvent their limitation in terms of mechanical performance. In the present study, we investigated the rheological/mechanical properties of both ionic- (iGG-MA) and photo-crosslinked methacrylated gellan gum (phGG-MA) hydrogels. Steady shear analysis, injectability and confined compression stress-relaxation tests were carried out. The injectability of the reactive solutions employed for the preparation of iGG-MA and phGG-MA hydrogels was first studied, then the zero-strain compressive modulus and permeability of the acellular hydrogels were
\end{abstract}

evaluated. In addition, human intervertebral disc (hIVD) cells encapsulated in both iGG-MA and phGG-MA hydrogels were cultured in vitro, and its mechanical properties also investigated under dynamic mechanical analysis at $37^{\circ} \mathrm{C}$ and $\mathrm{pH}$ 7.4. After 21 days of culturing, hIVD cells were alive (Calcein $\mathrm{AM})$ and the $E^{\prime}$ of ionic-crosslinked hydrogels and photo-crosslinked was higher than that observed for acellular hydrogels. Our study suggests that methacrylated gellan gum hydrogels present promising mechanical and biological performance as hIVD cells were producing extracellular matrix. (c) 2013 Wiley Periodicals, Inc. J Biomed Mater Res Part A: 00A:000-000, 2013.

Key Words: hydrogels, injectability, mechanical properties, methacrylated gellan gum, rheology

How to cite this article: Silva-Correia J, Gloria A, Oliveira MB, Mano JF, Oliveira JM, Ambrosio L, Reis RL. 2013. Rheological and mechanical properties of acellular and cell-laden methacrylated gellan gum hydrogels. J Biomed Mater Res Part A 2013:00A:000-000.

\section{INTRODUCTION}

Tissue engineering strategies aiming to regenerate intervertebral disc (IVD) tissue often rely on the use hydrogels, due to the number of advantages that these highly hydrated networks can offer. ${ }^{1,2}$ Hydrogels can be used as injectable scaffolds, being implanted in a minimally invasive manner and easily filling defects of any size and shape. These features thus improve the surgeons working efficiency and shorten the surgery time. These materials are also more advantageous as carriers for the delivery of cells and bioactive agents, in a spatially and temporally controlled manner. In addition, hydrogels can replicate a physiological fluid flow and provide a 3D micro-environment that favors the retention of a rounded morphology by encapsulated cells, ${ }^{3}$ and thus the induction of a chondrocytic phenotype and production of cartilaginous tissue. ${ }^{4,5}$ Hydrogels are also able to transduce mechanical loads to encapsulated cells and exert specific forces, similar to physiological forces, that can contribute to stimulate cells to achieve the desired phenotype. ${ }^{6,7}$ One of the factors that can compromise the use of hydrogels in tissue engineering applications is their limitation in terms of mechanical properties. Although hydrogels' mechanics can be modulated by altering the crosslinking density or the method of crosslinking (either physically or chemically), it must exist a balance between the necessary mechanical properties and cellular biocompatibility. ${ }^{2}$ Other cartilaginous tissues, such as articular cartilage or meniscus, which similarly to the IVD allow for efficient load bearing and distribution, and contribute to the flexibility in the joints of the body by providing low friction, can also be replaced by tissue-engineered hydrogels to repair the defects caused by degenerative diseases or traumatic

Correspondence to: J. Silva-Correia; e-mail: joana.correia@dep.uminho.pt

Contract grant sponsor: European Union funded Collaborative Project Disc Regeneration; contract grant number: NMP3-LA-2008-213904

Contract grant sponsor: Portuguese Foundation for Science and Technology (FCT) through POCTI and FEDER Programmes 
injuries. ${ }^{2}$ For these applications, the hydrogels' properties must be adjusted to best mimic the distinct natural behavior of each specific tissue aimed to regenerate. ${ }^{8}$

Degeneration of IVD has been characterized by nucleus pulposus (NP) loss of hydration and mechanical properties, ${ }^{9}$ associated with biochemical changes related to glycosaminoglycans and cell senescence. ${ }^{10}$

Several strategies have been exploited to restore the IVD functionality by means of regenerating NP tissue. Cell-based approaches involving stem cells, ${ }^{11}$ chondrocyte transplantation $^{12}$ and gene therapy ${ }^{13}$ are few strategies that are currently under pre-clinical investigation. Despite presenting regenerative advantages, most of the studies using acellular scaffolds, alone or combined with growth factors, ${ }^{14-16}$ and cell-laden scaffolds ${ }^{17}$ are still far from reaching the required biological and biomechanical performance. In this context, different chemical modifications of native hyaluronan (HA) have been performed to obtain chemically and mechanically robust materials such as a dodecylamide, HYADD $3^{\circledR}$, and a photo-linkable ester, HYAFF120 ${ }^{\circledR}$, suitably derived from HA. Accordingly, the viscoelastic properties of $\mathrm{HYADD}^{\circledR}{ }^{\circledR}$ and HYAFF120 ${ }^{\circledR}$ solutions were assessed before and after the injection through clinical catheters. ${ }^{18}$

In a recent study, Benz et al. ${ }^{19}$ have investigated the rheological and biological properties of serum albuminbased hydrogel, for its potential application as NP substitute. The in vitro and in vivo studies revealed that the hydrogels support encapsulation and cells were able to produce extracellular matrix, but no data on the mechanical properties of cell-laden hydrogels were assessed.

Recently, our group has been investigating different gellan gum hydrogels formulations ${ }^{3,20-22}$ for IVD tissue engineering. The in vitro and in vivo studies demonstrated promising results in respect to the hydrogels' biocompatibility, nonangiogenic ability and encapsulation efficiency.

This work aimed to investigate the rheological properties of both ionic- and photo-crosslinked methacrylated gellan gum (GG-MA) hydrogels for use as acellular and cellular NP substitutes. Steady shear measurements and confined compression stress-relaxation tests were performed. In addition, injectability tests were carried out using an in-house developed testing machine. The mechanical performance of cellladen ionic- and photo-crosslinked gellan gum hydrogels were also assessed under dynamic mechanical analysis for times up to 21 days of culturing. For the purpose of this work, human intervertebral disc cells were encapsulated within the hydrogels and a calcein-AM staining was performed to evaluate its viability up to 21 days of culturing.

\section{MATERIALS AND METHODS \\ Materials}

Low-acyl gellan gum, GG (Gelzan ${ }^{\mathrm{TM}} \mathrm{CM}$ ), glycidyl methacrylate, GMA (97\%) and methyl benzoylformate, MBF (98\%) were obtained from Sigma-Aldrich (USA).

\section{Synthesis of the methacrylated gellan gum}

Methacrylated gellan gum (GG-MA, $M_{\mathrm{W}}=70.6 \mathrm{kDa}$ ) was synthesized by reacting $\mathrm{GG}\left(M_{\mathrm{W}}=71.1 \mathrm{kDa}\right)$ with $\mathrm{GMA}$ as described elsewhere. ${ }^{3,22,23}$ Briefly, GG was added to distilled water at room temperature under constant agitation to obtain a final concentration of $1 \%(\mathrm{w} / \mathrm{v})$. The complete and homogeneous dispersion of the material was achieved after heating the solution at $90^{\circ} \mathrm{C}$. The GG solution was allowed to cool to room temperature and then GMA was added at 20 -fold molar excess in respect to the repeating unit of GG. The reaction mixture was adjusted to $\mathrm{pH} 8.5$ with $1 \mathrm{M}$ sodium hydroxide (NaOH; Panreac Química SAU, Spain). Then, the mixture was allowed to react for $24 \mathrm{~h}$ at room temperature under vigorous stirring. The $\mathrm{pH}$ was automatically adjusted to 8.5 with $1 \mathrm{M}$ $\mathrm{NaOH}$ during reaction. The reaction product was precipitated with 0.5 volumes of cold acetone (Panreac Química SAU, Spain) and purified by dialysis (cellulose membrane, $M_{\mathrm{W}}$ cutoff $12 \mathrm{kDa}$; Sigma-Aldrich, USA) against distilled water for 7 days to remove residual GMA. Finally, the dialyzed GG-MA was frozen at $-80^{\circ} \mathrm{C}$ and the powders were obtained after lyophilization (Telstar-Cryodos -80, Spain) for 7 days.

\section{Preparation of the ionic- and photo-crosslinked GG-MA hydrogel discs}

The ionic-crosslinked hydrogel discs were obtained by means of dissolving the GG-MA powders in distilled water at a final concentration of $2 \%(\mathrm{w} / \mathrm{v})$, under vigorous agitation and at room temperature. The gel was transferred to silicone moulds and discs were obtained by immersion in PBS (pH 7.4) for $30 \mathrm{~min}$.

The photo-crosslinked GG-MA hydrogel discs were produced by using a GG-MA solution at $2 \%(\mathrm{w} / \mathrm{v})$ concentration. After complete homogenization of the solution, the photo-initiator MBF was then added to a final concentration of $0.1 \%(\mathrm{w} / \mathrm{v})$. The gel was transferred to a silicone mould, and then hydrogel discs were obtained by exposure to ultraviolet light (366 nm; UV lamp Triwood 6/36, Bresciani srl., Italy) for $10 \mathrm{~min}$. The photo-crosslinked discs were further equilibrated in PBS (pH 7.4) for 30 min.

All discs were produced possessing a diameter of $11.5 \mathrm{~mm}$ and height of $1.5 \mathrm{~mm}$. For the preparation of sterile hydrogel discs, GG-MA powders sterilized under an ethylene oxide atmosphere were used. The materials were processed in a flow chamber cabinet with a different dimension, that is, $6 \mathrm{~mm}$ of diameter and $4 \mathrm{~mm}$ thickness. Discs dimensions were determined by the requirements of the analyses being performed.

\section{Mechanical and rheological analyses \\ Steady shear measurements. The viscosity as a function of the shear rate was evaluated through steady state shear measurements performed on the reactive solutions for the preparation of ionic- and photo-crosslinked GG-MA hydrogels. \\ All the measurements were carried out at a temperature of $37^{\circ} \mathrm{C}$ in a wide range of shear rate $\left(0.02-20 \mathrm{~s}^{-1}\right)$, using a rheometer (Gemini, Bohlin, Sweden).}

Injectability tests. The functional injectability of the reactive solutions employed for the preparation of ionic- and photo-crosslinked GG-MA hydrogels, was also investigated by means of an INSTRON 5566 testing machine, using a 
custom-made experimental setup equipped with an environmental chamber.

The injectability measurements were performed using a syringe with a $16 \mathrm{G}$ needle. The syringe (with an inner diameter of $4.5 \mathrm{~mm}$ ) was filled with the material that was then injected through the needle by applying a force on the syringe piston. This device was mounted on the INSTRON 5566 testing machine and the piston was driven at a constant and fixed speed of $40 \mathrm{~mm} \mathrm{~min}^{-1}$, thus controlling the injection rate and the apparent shear rate in the needle. All the tests were carried out at $37^{\circ} \mathrm{C}$. The load applied to the piston for injecting the material into and through the $16 \mathrm{G}$ needle was measured using a suitably calibrated load cell. An empty syringe equipped with a $16 \mathrm{G}$ needle was also tested at the same speed to estimate the effect due to the friction between syringe wall and piston.

Confined compression stress-relaxation tests. Confined compression stress-relaxation tests were performed on ionic- and photo-crosslinked GG-MA hydrogels. All the tests were carried out at $37^{\circ} \mathrm{C}$ using an INSTRON 5566 testing machine equipped with a porous indenter and a confining chamber. The cylindrical specimens were characterized by a diameter of $11.5 \mathrm{~mm}$ and a height (h) of 1.5 $\mathrm{mm}$. Three successive stress-relaxation cycles were applied corresponding to $5 \%$ strain increments (i.e., 5, 10, and $15 \%$ strain) and suitable dwell periods. As reported in the literature, ${ }^{24-27}$ several equations may be taken into consideration to study the case of uniaxial confined compression. Briefly, in the case of uniaxial confined compression tests, the constitutive law for the extra-stress tensor should be used:

$$
\sigma_{z}^{e}=\frac{1}{2} H A 0\left(\frac{\lambda^{2}-1}{\lambda^{2 \beta+1}}\right) \exp \left[\beta\left(\lambda^{2}-1\right)\right]
$$

where $H_{\mathrm{A} 0}$ is the zero-strain compressive modulus, $\beta$ is the nonlinear stiffening coefficient, $\lambda$ is the stretch ratio that is related to the axial strain $(\delta \mathrm{u} / \delta \mathrm{z})$, and $u$ is the displacement.

The hydraulic permeability $k$ is related to the deformation by the following equation:

$$
k=k_{0}\left(\frac{\lambda-\varphi_{0}^{S}}{1-\varphi_{0}^{s}}\right)^{2} \exp \left[M\left(\lambda^{2}-1\right) / 2\right]
$$

where $M$ is the nondimensional nonlinear permeability coefficient that is a measure of the sensitivity to the deformation, $k_{0}$ is the zero-strain permeability, $\varphi_{0}^{\mathrm{s}}{ }_{0}$ is the solid volume fraction at the reference state.

Using the theoretical approach, the governing equations for finite deformation can be simplified to produce the following one-dimensional nonlinear partial differential equation:

$$
\frac{\delta \sigma^{e}}{\delta \lambda} \frac{\delta^{2} u}{\delta z^{2}}=\frac{\lambda}{k} \frac{\delta u}{\delta t} 0<z<h
$$

The following initial and boundary conditions were considered:

$$
\begin{aligned}
& u(h, t)=0 u(0, t)=\left\{\frac{V_{0} t \rightarrow 0 \leq t \leq t_{0}}{V_{0} t_{0} \rightarrow t>t_{0}}\right\} \\
& u(z, 0)=0
\end{aligned}
$$

where, $V_{0}$ is the displacement rate and $t_{0}$ is the ramp time.

Taking into consideration the above mentioned approach, the stress-relaxation data were used to provide an evaluation of the properties of ionic- and photo-crosslinked GG-MA hydrogels.

Statistical analysis. Results are reported as mean \pm standard deviation (SD) and were analyzed using analysis of variance (ANOVA) followed by Bonferroni post-hoc comparisons. Statistical differences were set at $p<0.05$.

\section{In vitro study}

Cells isolation and culturing. Human intervertebral disc (hIVD) cells were isolated using an enzymatic digestionbased method from herniated tissue obtained from a female patient (age 36) submitted to surgery. The human biological tissue was collected in accordance to the Ethics Committee at the Centro Hospitalar Póvoa de Varzim-Vila do Conde. Briefly, the extracted tissue was placed in PBS solution ( $\mathrm{pH} 7.4)$ and washed several times with PBS containing $1 \%(\mathrm{v} / \mathrm{v})$ antibiotic-antimycotic (A/B) mixture (Invitrogen, USA), containing $10,000 \mathrm{U} \mathrm{mL}^{-1}$ penicillin $\mathrm{G}$ sodium, 10,000 $\mu \mathrm{g} \mathrm{mL} \mathrm{mL}^{-1}$ streptomycin sulfate and $25 \mu \mathrm{g}$ $\mathrm{mL}^{-1}$ amphotericin B as Fungizone ${ }^{\circledR}$ Antimycotic in $0.85 \%$ saline, until total removal of blood or other bodily contaminants. Prior to digestion, the removed tissue was cut in small pieces to increase the efficiency of digestion and obvious dense annulus-like tissue was discarded. Human tissue digestion was performed by incubation at $37^{\circ} \mathrm{C}$ in a humidified atmosphere of $5 \% \mathrm{CO}_{2}$ for $24 \mathrm{~h}$ in $20 \mathrm{~mL}$ of cell medium Dulbecco's modified Eagle's medium:Nutrient mixture F12 1:1 (DMEM:F12; Invitrogen, USA) containing $0.3 \%(\mathrm{w} / \mathrm{v})$ collagenase type II (Sigma-Aldrich, USA) and supplemented with $10 \%(\mathrm{v} / \mathrm{v})$ fetal bovine serum (FBS; Biochrom, Germany) and $1 \%(\mathrm{v} / \mathrm{v})$ of an $\mathrm{A} / \mathrm{B}$ mixture (Invitrogen, USA). Following digestion, cells were separated from the remaining tissue debris by using a cell strainer $(100 \mu \mathrm{m})$. The isolated hIVD cells were expanded in DMEM:F12 (1:1) medium supplemented with 10\% (v/v) FBS and $1 \%(\mathrm{v} / \mathrm{v})$ of an A/B mixture in standard culture conditions until reaching confluence. The medium was changed every 3 days.

Encapsulation of human disc cells in the ionic- and photo-crosslinked GG-MA hydrogels. Isolated hIVD cells were used at passage 4-5 for encapsulation within the ionicand photo-crosslinked GG-MA hydrogel discs. Confluent cells were detached from the culture flasks using trypsin $(0.25 \%$ trypsin/EDTA solution, Sigma-Aldrich, USA) and a diluted cell suspension was prepared and centrifuged at 1200 


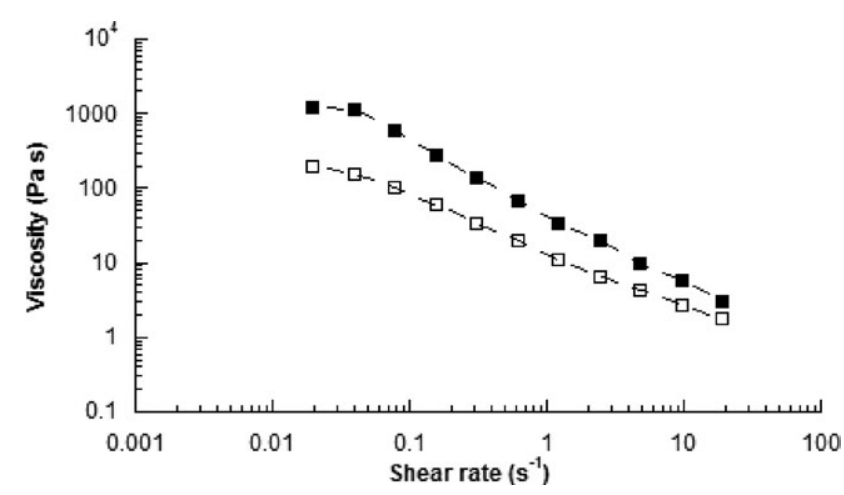

FIGURE 1. Viscosity as function of shear rate: reactive solutions employed for the preparation of ionic- $(\square)$ and photo-crosslinked ( GG-MA hydrogels.

rpm for $5 \mathrm{~min}$. Prior encapsulation of hIVD cells in the ionic- and photo-crosslinked GG-MA hydrogels, the medium was completely aspirated and the cell pellet was re-suspended in the respective hydrogel solution, that is, GG-MA or MBF-containing GG-MA solution. The cell-loaded hydrogels were produced in cylindrical silicone moulds with 6 mm diameter by using $2 \times 10^{5}$ cells per $100 \mu \mathrm{L}$ of hydrogel. The hydrogel discs with encapsulated hIVD cells were either ionic- (in PBS solution) or photo-crosslinked (UV light at $366 \mathrm{~nm}$ for $6 \mathrm{~min}$ ). Afterwards, hIVD cells/hydrogel discs were cultured in complete DMEM:F12 culture medium at $37^{\circ} \mathrm{C}$ and in a $5 \% \mathrm{CO}_{2}$ atmosphere for different periods of culturing, that is, $2 \mathrm{~h}, 1,3,7,14$, and $21 \mathrm{~d}$. Discs without cells (controls) were also produced and incubated in similar conditions. The medium was changed every 2 days.

Dynamic mechanical analysis (DMA) of the human disc cells-loaded GG-MA hydrogels. The mechanical behavior of the ionic- and photo-crosslinked GG-MA hydrogel discs and respective hIVD cell-loaded discs was characterized by DMA, after each culturing period. The viscoelastic measurements were performed using a TRITEC8000B DMA from Triton Technology (UK), equipped with the compressive mode. The measurements were carried out at $37^{\circ} \mathrm{C}$ temperature. The hydrogel discs were always analyzed immersed in a liquid bath placed in a Teflon ${ }^{\circledR}$ reservoir. The geometry of the samples was then measured accurately and the samples were clamped in the DMA apparatus and immersed in the PBS solution ( $\mathrm{pH}$ 7.4). After equilibration at $37^{\circ} \mathrm{C}$, the DMA spectra were obtained during a frequency scan between 0.1 and 15 Hz. The experiments were performed under constant strain amplitude $(50 \mu \mathrm{m})$. A small preload was applied to each sample to ensure that the entire disc surface was in contact with the compression plates before testing and the distance between plates was equal for all scaffolds being tested. Two independent experiments were conducted, each with six samples for each condition $(n=6)$. Results are presented as mean $\pm \mathrm{SD}$ and were analyzed using two-way ANOVA followed by Bonferroni post-hoc comparisons. Statistical differences were set at $p<0.05$, using the GraphPad software (GraphPad Prism, San Diego, CA).
Calcein AM assay. Cell viability was evaluated after each time of culturing (in triplicate) by performing Calcein AM staining. The experiment was carried out prior to each DMA experiment $(n=6)$. Briefly, a Calcein AM (Molecular Probes, USA) solution was prepared in serum-free DMEM:F12 (1:1) culture medium without phenol red in the proportion of $1 /$ 1000. The cell-loaded ionic- and photo-crosslinked GG-MA hydrogel discs were transferred from the TCPS culturing plates and incubated in $1 \mathrm{~mL}$ of Calcein $\mathrm{AM}$ solution for 15-30 min at $37^{\circ} \mathrm{C}$ and with $5 \% \mathrm{CO}_{2}$. After several washes with sterile PBS solution, the samples were observed under fluorescence microscopy using an Axio Imager.Z1m light microscope (Zeiss, Germany) with an attached digital camera AxioCam MRm (Zeiss, Germany) connected to the AxioVision image processing software (Zeiss, Germany).

\section{RESULTS AND DISCUSSION}

\section{Mechanical and rheological analyses}

Steady shear measurements. Steady state shear measurements performed on the reactive solutions used for the preparation of ionic- and photo-crosslinked GG-MA hydrogels have evidenced a non-Newtonian behavior since viscosity decreases as shear rate increases (shear thinning), thus suggesting the possibility to easily inject them (Fig. 1).

In particular, when the shear rate rises from 0.02 to 20 $\mathrm{s}^{-1}$, reactive solutions employed for the preparation of ionic-crosslinked GG-MA hydrogels have shown a viscosity that decreases from $192.7 \pm 21.8 \mathrm{~Pa} \mathrm{~s}^{-1}$ to $1.8 \pm 0.2 \mathrm{~Pa}$ $\mathrm{s}^{-1}$, while higher viscosity values (from $1203.4 \pm 122.7 \mathrm{~Pa}$ $\mathrm{s}^{-1}$ to $2.9 \pm 0.3 \mathrm{~Pa} \mathrm{~s}^{-1}$ ) have been achieved in the case of those used for photo-crosslinked GG-MA hydrogels.

However, this difference in terms of viscosity values seems to be more evident at low shear rates (Fig. 1). The differences observed within the investigated range of shear rate are statistically significant. It is also worth noting that the gel formation process occurs in a reproducible manner.

Injectability tests. The injectability of reactive solutions has been evaluated from the obtained load-displacement curves.

The above mentioned solutions have generally shown similar load-displacement curves: a linear region is initially observed at low displacement values. After a maximum load occurred, load values sharply dropped, then fluctuating and reaching a plateau. At the end of the plateau-like region the material was completely injected (Fig. 2).

As evidenced by the load-displacement curve for the empty syringe, the effect of friction between the piston and syringe wall is significant at shorter times (and, hence, at the beginning of the syringe piston displacement).

Even though steady shear tests have highlighted differences in terms of viscosity values especially at low shear rates, both reactive solutions employed for the preparation of ionic- and photo-crosslinked GG-MA hydrogels have provided similar values of maximum load $(2.39 \pm 0.27 \mathrm{~N}$ and $2.40 \pm 0.29 \mathrm{~N}$, respectively) and plateau load (0.35 \pm 0.04 $\mathrm{N}$ and $0.34 \pm 0.04 \mathrm{~N}$, respectively) that are close to those of the empty syringe $(2.34 \pm 0.22 \mathrm{~N}$ and $0.30 \pm 0.03 \mathrm{~N})$. 


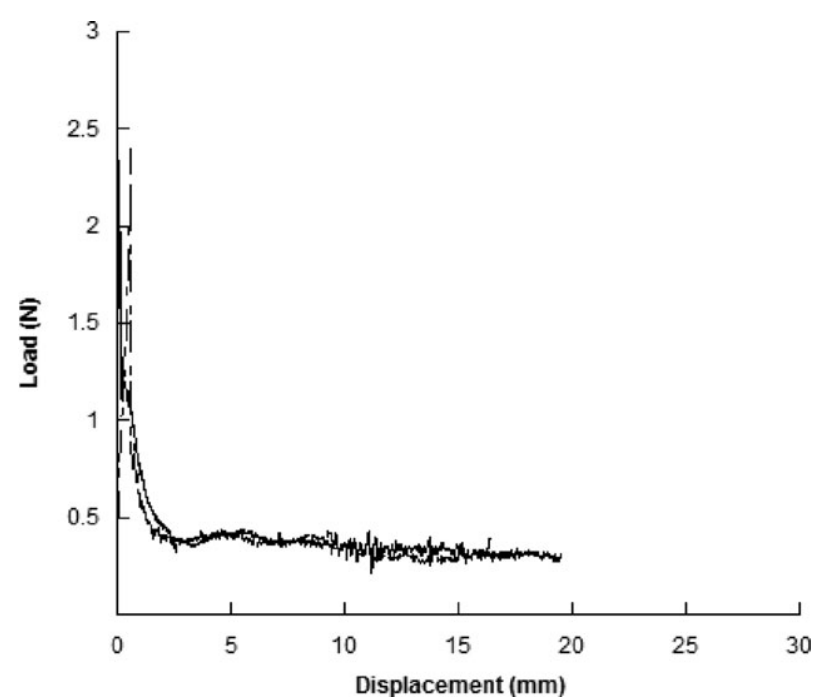

FIGURE 2. Typical load-displacement curves obtained from a solution injected into and through the $16 \mathrm{G}$ needle (dashed line), and from an empty syringe (solid line).

Furthermore, no significant differences were found. As already discussed, it appears clear that the values of maximum load also include the contribution of the initial friction. For this reason, the maximum load may represent the initial resistance to material flow, whilst the plateau load may provide important information on the continuous flow of material through the needle.

Injectability tests have demonstrated that the reactive chemical solutions employed for the preparation of ionic- and photo-crosslinked GG-MA hydrogels can be easily injected into and through a $16 \mathrm{G}$ needle. With regard to the employed $16 \mathrm{G}$ needle, in the literature a wide range of clinical catheters is reported (14-29 G). Accordingly, several studies have been taken into account the possibility to use different needles for injecting nucleus substitutes or for analyzing the eventual effects of the needle diameter on the disc degeneration. ${ }^{28-30}$ The present work should be considered as a first approach in analyzing the functional injectability of the employed reactive solutions for the preparation of iGG-MA and phGG-MA hydrogels, and a $16 \mathrm{G}$ needle has been selected as an example. From a functional point-of-view, considering the liquid-like behavior of the employed reactive solutions as well as their shear thinning, a small diameter should not provide problems during the injection. Clearly, a future work will be driven toward the analysis of the injectability of these reactive solutions using different needles and injection speed that would provide interesting rheological/functional features (i.e., apparent shear rate, apparent shear viscosity, extrusion time, flow rate) to be eventually used for the design of an appropriate injection device. Therefore, a compromise should be always found between the required injectability/rheological features and the size defects in the annulus due to a specific needle diameter.

Confined compression stress-relaxation tests. Using the approach described in the "Materials and Methods" section, the stress-relaxation curves were used to assess the values
TABLE I. Zero-Strain Compressive Modulus $\left(H_{\mathrm{A} 0}\right)$ and Nonlinear Stiffening Coefficient $(\beta)$, Reported as Mean Value \pm Standard Deviation

\begin{tabular}{lcc}
\hline Materials & $H_{\mathrm{A} 0}(\mathrm{kPa})$ & $\beta$ \\
\hline lonic-crosslinked GG-MA & $10.5 \pm 3.1$ & $0.5 \pm 0.1$ \\
Photo-crosslinked GG-MA & $7.0 \pm 2.1$ & $3.0 \pm 1.2$ \\
\hline
\end{tabular}

of $H_{\mathrm{A} 0}, \beta, k_{0}$ and $M$ for ionic- and photo-crosslinked GG-MA hydrogels (Tables I and II).

Briefly, to determine $H_{\mathrm{A} 0}$ and $\beta$, the equilibrium stressstretch data were curve-fitted using the constitutive law defined by Eq. (1) and a nonlinear least-squares regression procedure. Employing the obtained values of $H_{\mathrm{A} 0}$ and $\beta$, the parameters describing the hydraulic permeability $\left[k_{0}\right.$ and $M$, reported in Eq. (2)] were then evaluated by a non-linear regression of the numerical solution for the axial stress [Eq. (3)] to the experimental stress relaxation data, as reported in the literature. ${ }^{25-27}$ However, the observed differences (Tables I and II) are statistically significant.

Previous studies have determined the confined compression and permeability values of the $\mathrm{NP}^{27,31-33}$ The mechanical properties derived from confined compression experiments performed on bovine NP by Périé et al. ${ }^{27}$ resulted in a zero-strain compressive modulus value of 310 $\pm 40 \mathrm{kPa}$, which is higher than the values obtained for the ionic- $(10.5 \pm 3.1 \mathrm{kPa})$ and photo-crosslinked $(7.0 \pm 2.1$ $\mathrm{kPa}$ ) hydrogels. Regarding the permeability, in that same study the value obtained for bovine NP was $0.67 \pm 0.09 \times$ $10^{-15} \mathrm{~m}^{4} \mathrm{~N}^{-1} \mathrm{~s}^{-1}$. Other studies have determined the permeability in both human and bovine disc nucleus and also by finite element analysis. ${ }^{31-33}$ The measured permeability of the NP tissue was comprised between 0.32 and $2.08 \times 10^{-15}$ $\mathrm{m}^{4} \mathrm{~N}^{-1} \mathrm{~s}^{-1}$, which was consistent with the predicted permeability $\left(0.29-0.91 \times 10^{-15} \mathrm{~m}^{4} \mathrm{~N}^{-1} \mathrm{~s}^{-1}\right)$. Other reports have also determined the hydraulic permeability of the NP using mathematical models of the tissue. Riches et al. ${ }^{34}$ reported that the zero-strain permeability was 1.17-1.89 $\times 10^{-15}$ $\mathrm{m}^{4} \mathrm{~N}^{-1} \mathrm{~s}^{-1}$ and the nondimensional nonlinear permeability coefficient was in the range of 3.41-4.17. Our results relative to $M$ are of the same order of magnitude to that reported in the literature, while $\mathrm{H}_{\mathrm{A} 0}$ and $\mathrm{k}_{0}$ are slightly inferior. However, the mechanical and rheological data on GG-based hydrogels are encouraging as compared to other hydrogels ${ }^{35}$ and deserves further investigation as NP substitutes.

\section{In vitro study}

Mechanical properties of the acellular and cell-loaded hydrogels. The effect of encapsulating hIVD cells (Fig. 3) on the mechanical properties of the hydrogels was evaluated

TABLE II. Zero-Strain Permeability $\left(\boldsymbol{k}_{0}\right)$ and Nondimensional Nonlinear Permeability Coefficient $(M)$, Reported as Mean Value \pm Standard Deviation

\begin{tabular}{lcc}
\hline Materials & $k_{0}\left(\times 10^{-13} \mathrm{~m}^{4} \mathrm{~N}^{-1} \mathrm{~s}^{-1}\right)$ & $M$ \\
\hline lonic-crosslinked GG-MA & $1.7 \pm 0.6$ & $3.2 \pm 1.0$ \\
Photo-crosslinked GG-MA & $5.0 \pm 1.9$ & $2.7 \pm 0.7$ \\
\hline
\end{tabular}




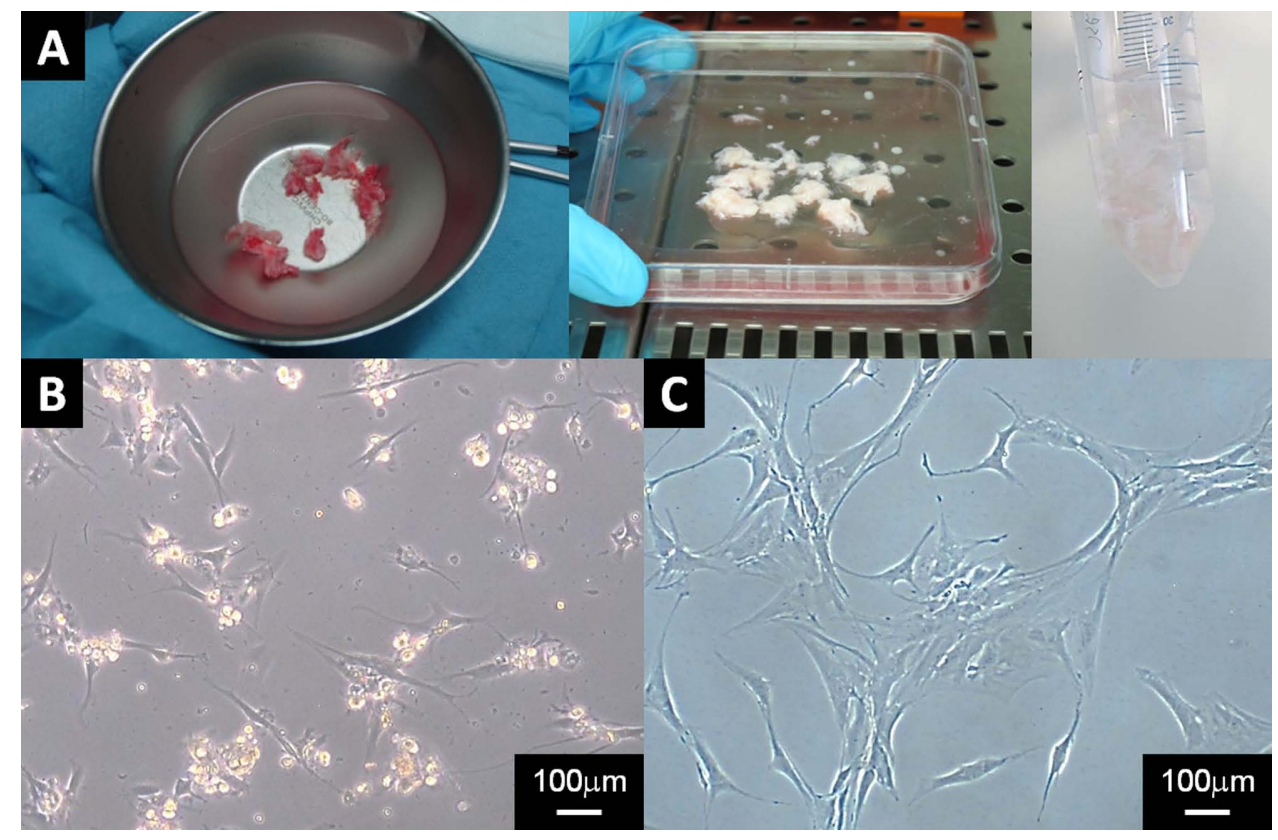

FIGURE 3. Isolation of human intervertebral disc (hIVD) cells from herniated tissue obtained by surgery: (A) tissue removal, washing and enzymatic digestion, (B) hIVD cell morphology 4 days after isolation in a $2 \mathrm{D}$ culturing in static conditions and (C) hIVD cell morphology prior to encapsulation. [Color figure can be viewed in the online issue, which is available at wileyonlinelibrary.com.]

by DMA along different periods of culturing (Fig. 4). As controls, acellular discs were also characterized in relation to their mechanical performance. By one hand, this study allowed evaluating the influence of encapsulating cells on the mechanical properties of the hydrogels and following their effect during culturing; and on the other hand, it allowed studying the influence of specific incubation times on the acellular hydrogels' properties. The results have shown that cell encapsulation seems to slightly decrease the storage modulus $\left(E^{\prime}\right)$ of both ionic- (from $83.0 \pm 11.4$ to $75.8 \pm 14.1 \mathrm{kPa}$ ) and photo-crosslinked (from $87.8 \pm 16.6$ to $73.3 \pm 15.3 \mathrm{kPa}$ ) GG-MA hydrogel discs just after cell encapsulation and $2 \mathrm{~h}$ of immersion in culture medium [Fig. $4(\mathrm{~A}, \mathrm{~B})$; for comparison purposes, the results obtained at 1 $\mathrm{Hz}$ are used]. For the subsequent periods of culturing (i.e., from 1 up to 7 days) both cell loading and culturing time did not affect the mechanical properties of ionic- and photocrosslinked GG-MA hydrogel discs [Fig. 4(C-H)]. Although the incorporation of cells appears to have an immediate negative effect on the mechanical performance of the hydrogels, which is recovered after 1 day of culturing [Fig. $4(C, D)]$, the observed differences are not statistically significant. The data for longer culturing times (i.e., 14 and 21 days), revealed an increase in the mechanical properties of both ionic- and photo-crosslinked hydrogel discs [Fig. 4(IL)]. As shown in Figure 4(I,J), after 14 days of culturing, the $E^{\prime}$ value of the cell-loaded ionic-crosslinked hydrogel discs $(96.4 \pm 18.6 \mathrm{kPa})$ was higher (although not statistically different) as compared to the acellular discs (85.8 $\pm 9.1 \mathrm{kPa})$ cultured in the same conditions. After 21 days of culturing [Fig. 4(K,L)], this increase became more evident for the ionic-crosslinked hydrogels (from $80.4 \pm 20.6$ to $115.8 \pm$ $21.6 \mathrm{kPa}$ ), and started to be observed as well in the photo-crosslinked discs (from $85.8 \pm 4.2$ to $98.4 \pm 0.3$ $\mathrm{kPa}$ ). Statistical analysis has revealed that only the differences obtained for the ionic-crosslinked hydrogels are statistically significant, as indicated in Figure $4(\mathrm{~K}, \mathrm{~L})\left({ }^{*} p<0.05\right)$. In a previous work, Bahney et al. $^{36}$ have also observed an increase of $E^{\prime}$ values after 12 weeks of culturing, consistent with the production of extracellular matrix and alteration of collagen type II distribution by hMSCs photo-encapsulated in matrix metalloproteinase 7 (MMP-7)-sensitive scaffolds. In these MMP-7-sensitive constructs, the formation of neocartilage occurred concomitantly with the degradation of the scaffolds, which was translated into an increase in the mechanical performance. The $E^{\prime}$ values obtained for cellloaded hydrogels after 21 days of cell culture, that is, 115.8 $\pm 21.6 \mathrm{kPa}$ for ionic-crosslinked hydrogels and $98.4 \pm 0.3$ $\mathrm{kPa}$ for photo-crosslinked hydrogels, are close to the range of values measured for sheep IVDs $(64 \pm 28 \mathrm{kPa})^{37}$ and also in the same order of the apparent dynamic modulus measured in rat caudal spine (around $250 \mathrm{kPa}$ at $1 \mathrm{~Hz}$ ). ${ }^{38}$

Figure 4 also demonstrates that the acellular ionic- and photo-crosslinked GG-MA hydrogels were able to maintain their integrity in vitro, since no significant differences $(p>$ 0.05 ) were found in the $E^{\prime}$ values (at $1 \mathrm{~Hz}$ ) of both types of hydrogel throughout the period of culturing studied.

The correct function of the IVD is dependent on its ability to dissipate mechanical energy. The lack of this ability may lead to the development of adjacent segment disease which is often observed after disc surgery. As such, tissue-engineered IVDs must be able to show the damping capacity of the native disc, overcoming this drawback which is frequently associated to the currently available treatments. ${ }^{38}$ The damping $(\tan \delta$ ) values of the cell-loaded hydrogels were higher than 0.2 , showing the viscoelastic behavior of the tissue engineered 
A

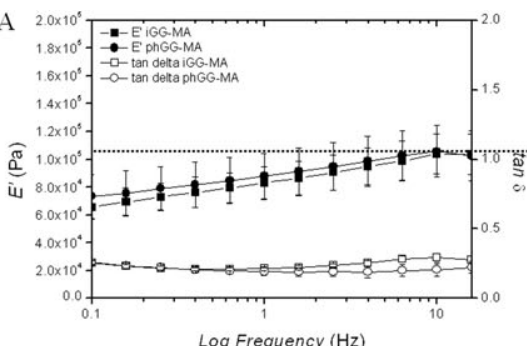

C

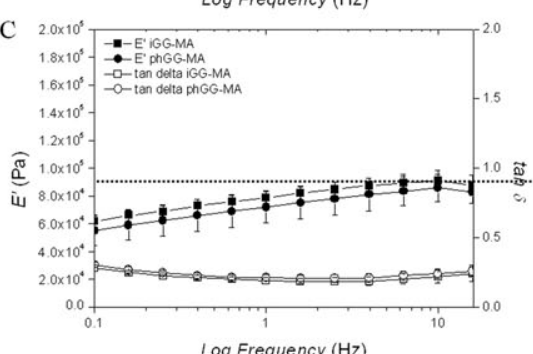

E
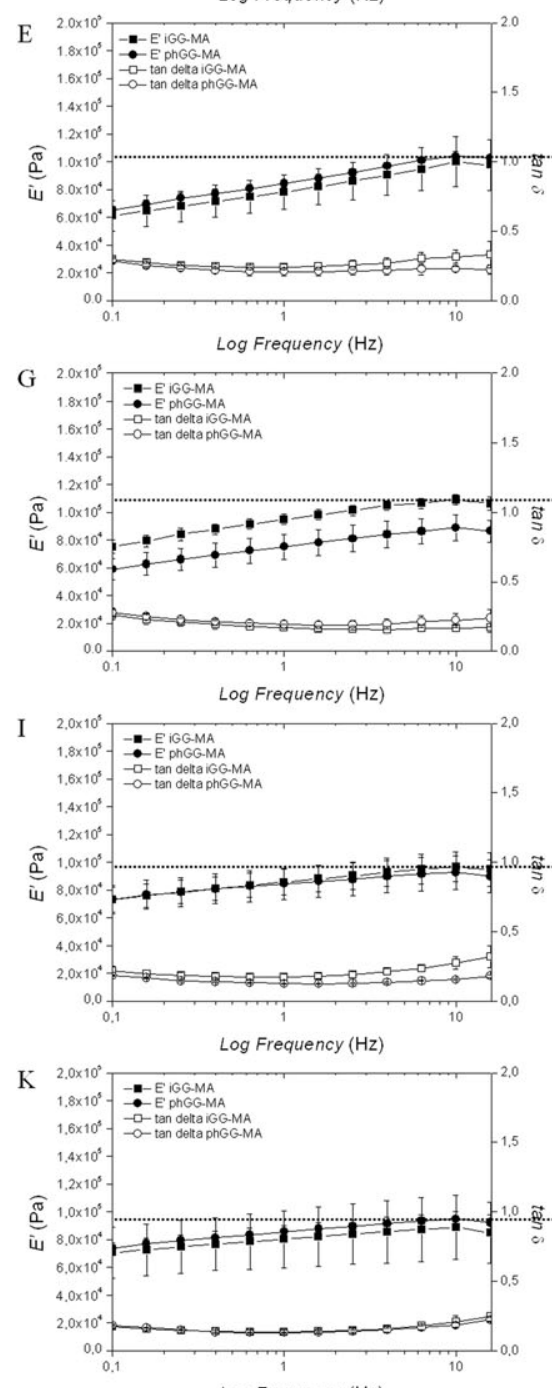

Log Frequency $(\mathrm{Hz})$

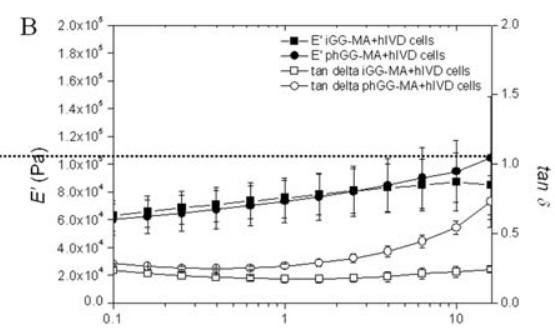

$\log$ Frequency $(\mathrm{Hz})$

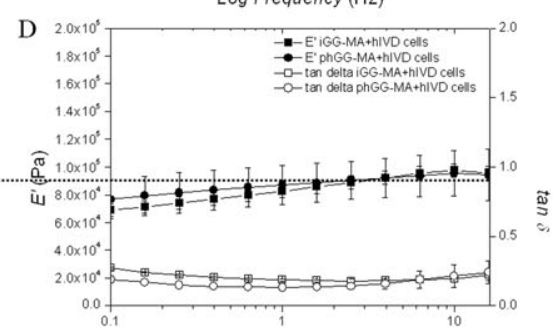

Log Frequency $(\mathrm{Hz})$

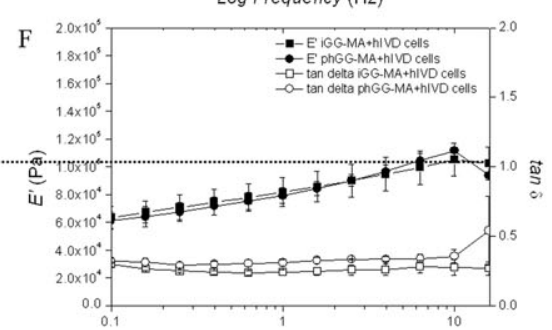

Log Frequency $(\mathrm{Hz})$

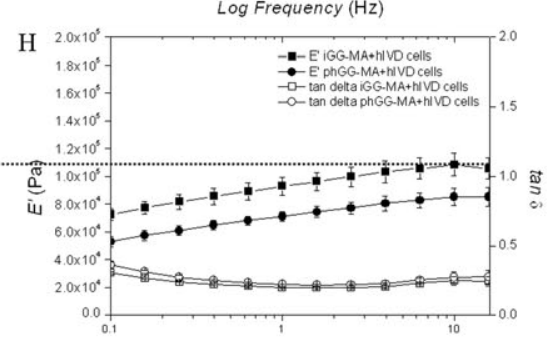

Log Frequency $(\mathrm{Hz})$

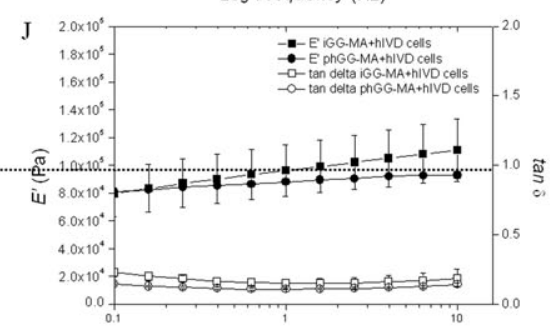

Log Frequency $(\mathrm{Hz})$

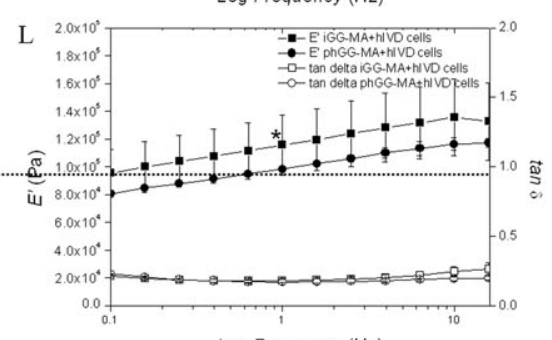

Log Frequency $(\mathrm{Hz})$

FIGURE 4. Dynamic mechanical analysis of ionic- (iGG-MA) and photo-crosslinked (phGG-MA) methacrylated gellan gum hydrogel discs after immersion in culture medium for $2 \mathrm{~h}(\mathrm{~A}-\mathrm{B}), 1$ day (C-D), 3 days (E-F), 7 days $(\mathrm{G}-\mathrm{H}), 14$ days (I-J), and 21 days (K-L), showing the storage modulus $\left(E^{\prime}\right)$ and loss factor $(\tan \delta)$ measured in PBS at $37^{\circ} \mathrm{C}$. Statistical analysis was performed based on the values obtained at $1 \mathrm{~Hz}$ and using a twoway ANOVA followed by Bonferroni's post test $(* 0<0.05)$. 

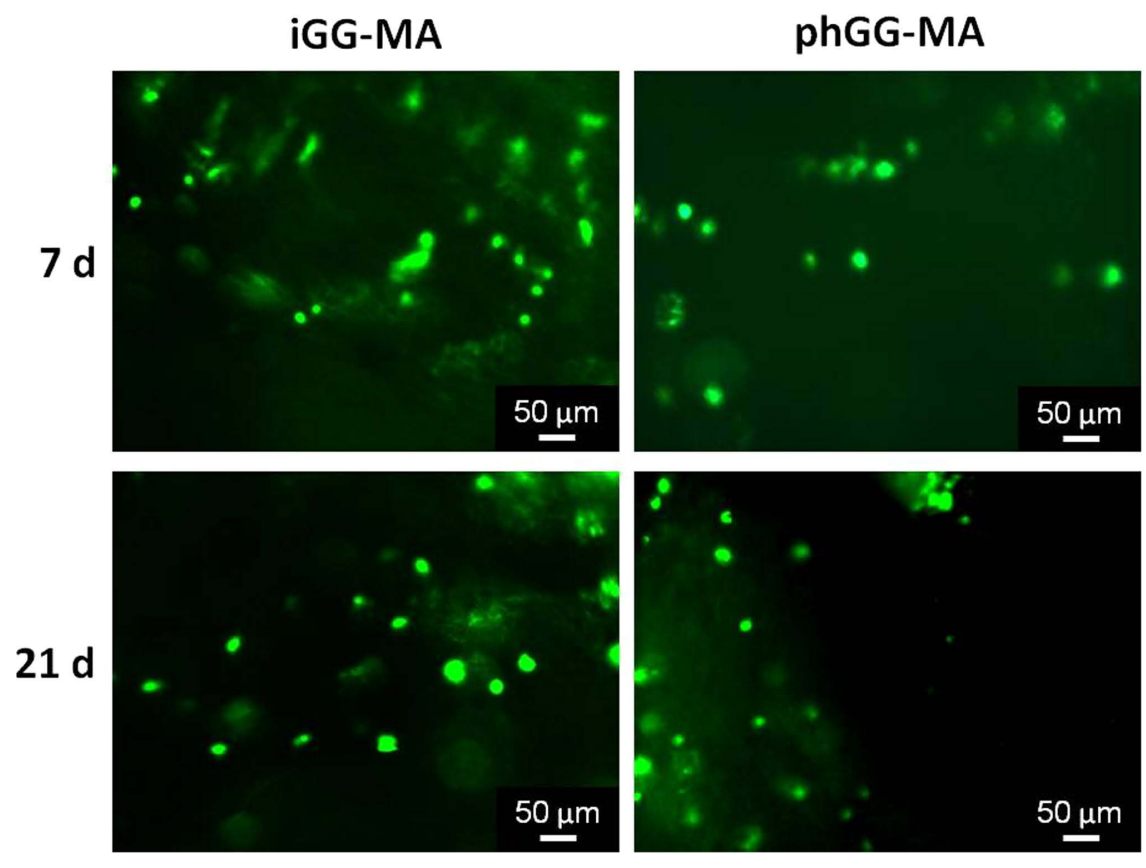

FIGURE 5. Fluorescence microscopy images of hIVD cells encapsulated within ionic- (iGG-MA) and photo-crosslinked (phGG-MA) methacrylated gellan gum hydrogels, after 7 and 21 days of culturing. The cells were stained with Calcein AM (green color corresponds to live cells), prior observation, and images were acquired from cross-sections of the hydrogel discs. [Color figure can be viewed in the online issue, which is available at wileyonlinelibrary.com.]

structures and, thus, their ability to dissipate energy during cyclic stimuli. While in the acellular hydrogels the damping values showed a tendency to decrease with the time of incubation in cell culture medium (mainly evident after 14 and 21 days), in the cell-encapsulated hydrogels the $\tan \delta$ values increased after 3 days of cell culture and kept values higher than 0.2 even after 21 days of cell culture.

Cell viability. To confirm the viability of cells encapsulated in the discs tested by DMA, at least three discs from each period of culturing was evaluated by Calcein AM staining. Figure 5 shows the microscopy images of hIVD cells encapsulated within ionic- and photo-crosslinked GG-MA hydrogels after 7 and 21 days of culturing (data relative to the other periods of culturing not shown). From Figure 5, it can be seen that hIVD cells were successfully encapsulated into the ionic- and photo-crosslinked GG-MA hydrogels, were generally well dispersed within the hydrogels' matrices, and maintained its typical rounded morphology during the culturing period. Calcein AM staining has shown that the hIVD cells were viable for all the periods tested (data not shown) and up to 21 days of culturing (Fig. 5), as observed by the green fluorescence. Similar results were observed in a previous study, ${ }^{3}$ where the encapsulation efficiency of these GGMA hydrogels was demonstrated by performing encapsulation studies with hIVD cells. In the present work, the cell viability assay is used to certify that the cells are alive in the moment of mechanical analysis.

\section{CONCLUSIONS}

In this study, ionic- and photo-crosslinked methacrylated gellan gum hydrogels' rheological properties and injectability were analyzed. Ionic- and photo-crosslinked methacrylated gellan gum hydrogels are stable, can be processed in a reproducible manner and possess adequate biomechanical features for being implanted using minimally invasive procedures. From in vitro results, it was possible to observe that the mechanical properties of cell-laden hydrogels increased, which could be related to the viability and production of extracellular matrix by hIVD cells. Our data demonstrated that both ionic- and photo-crosslinked methacrylated gellan gum hydrogels are promising biomaterials for cell encapsulation and easily allow gelation to occur before or after injection. These properties, together with the previously described characteristics of the methacrylated gellan gum hydrogels, are interesting for being tested in cellular-based tissue engineering strategies aimed to restore the functionality of IVD.

\section{ACKNOWLEDGMENTS}

The authors have no relevant affiliations or financial involvement with any organization or entity with a financial interest in or financial conflict with the subject matter or materials discussed in the manuscript. This includes employment, consultancies, honoraria, stock ownership or potions, expert testimony, grants or patents received or pending, or royalties. No writing assistance was utilized in the production of this manuscript.

\section{REFERENCES}

1. Lum L, Elisseeff J. Injectable hydrogels for cartilage tissue engineering. In: Ashammakhi N, Ferretti P, editors. Topics in Tissue Engineering. Oulu: University of Oulu; 2003. p 1-25.

2. Chung $C$, Burdick JA. Engineering cartilage tissue. Adv Drug Deliv Rev 2008;60:243-262.

3. Silva-Correia J, Zavan B, Vindigni V, Silva TH, Oliveira JM, Abatangelo G, Reis RL. Biocompatibility evaluation of ionic- and 
photo-crosslinked methacrylated gellan gum hydrogels: In vitro and in vivo study. Adv Healthc Mater 2012; doi:10.1002/adhm. 201200256.

4. Oliveira JT, Gardel LS, Rada T, Martins L, Gomes ME, Reis RL. Injectable gellan gum hydrogels with autologous cells for the treatment of rabbit articular cartilage defects. J Orthop Res 2010; 28:1193-1199.

5. Oliveira JT, Santos TC, Martins L, Picciochi R, Marques AP, Castro AG, Neves NM, Mano JF, Reis RL. Gellan gum injectable hydrogels for cartilage tissue engineering applications: in vitro studies and preliminary in vivo evaluation. Tissue Eng A 2010;16:343-353.

6. Kock L, van Donkelaar C, Ito K. Tissue engineering of functional articular cartilage: The current status. Cell Tissue Res 2012;347: 613-627.

7. Chung C, Erickson IE, Mauck RL, Burdick JA. Differential behavior of auricular and articular chondrocytes in hyaluronic acid hydrogels. Tissue Eng A 2008;14:1121-1131.

8. Almarza AJ, Athanasiou KA. Design characteristics for the tissue engineering of cartilaginous tissues. Ann Biomed Eng 2004;32: 2-17.

9. Nerurkar NL, Elliott DM, Mauck RL. Mechanical design criteria for intervertebral disc tissue engineering. J Biomech 2010;43: 1017-1030.

10. Gruber HE, Ingram JA, Norton HJ, Hanley ENJ. Senescence in cells of the aging and degenerating intervertebral disc: Immunolocalization of senescence-associated beta-galactosidase in human and sand rat discs. Spine 2007:32:321-327.

11. Vadalà G, Denaro E, Sobajima S, Kang JD, Gilbertson LG. Stem cell therapy for intervertebral disc degeneration: In vitro study. J Bone Joint Surg Br 2005;87-B:204-205.

12. Meisel HJ, Siodla V, Ganey T, Minkus Y, Hutton WC, Alasevic OJ. Clinical experience in cell-based therapeutics: Disc chondrocyte transplantation: A treatment for degenerated or damaged intervertebral disc. Biomol Eng 2007;24:5-21.

13. Cassinelli EH, Hall RA, Kang JD. Biochemistry of intervertebral disc degeneration and the potential for gene therapy applications. Spine J 2001;1:205-214.

14. Akeda K, An HS, Pichika R, Attawia M, Thonar EJ, Lenz ME Uchida A, Masuda K. Platelet-rich plasma (PRP) stimulates the extracellular matrix metabolism of porcine nucleus pulposus and anulus fibrosus cells cultured in alginate beads. Spine 2006;31 959-966.

15. Liang CZ, Li H, Tao YQ, Zhou XP, Yang ZR, Xiao YX, Li FC, Han B, Chen QX. Dual delivery for stem cell differentiation using dexamethasone and bFGF in/on polymeric microspheres as a cell carrier for nucleus pulposus regeneration. J Mater Sci Mater Med 2012;23:1097-1107.

16. Su W-Y, Chen Y-C, Lin F-H. Injectable oxidized hyaluronic acid/ adipic acid dihydrazide hydrogel for nucleus pulposus regeneration. Acta Biomater 2010;6:3044-3055.

17. Nesti LJ, Li WJ, Shanti RM, Jiang YJ, Jackson W, Freedman BA, Kuklo TR, Giuliani JR, Tuan RS. Intervertebral disc tissue engineering using a novel hyaluronic acid-nanofibrous scaffold (HANFS) amalgam. Tissue Eng A 2008;14:1527-1537.

18. Gloria A, Borzacchiello A, Causa F, Ambrosio L. Rheological Characterization of Hyaluronic Acid Derivatives as Injectable Materials Toward Nucleus Pulposus Regeneration. J Biomater Appl 2012 26:745-759.

19. Benz K, Stippich C, Osswald C, Gaissmaier C, Lembert N, Badke A, Steck E, Aicher W, Mollenhauer J. Rheological and biologica properties of a hydrogel support for cells intended for intervertebral disc repair. BMC Musculoskelet Disord 2012;13:1-13.

20. Pereira DR, Silva-Correia J, Caridade SG, Oliveira JT, Sousa RA Salgado AJ, Oliveira JM, Mano JF, Sousa N, Reis RL. Develop ment of gellan gum-based microparticles/hydrogel matrices for application in the intervertebral disc regeneration. Tissue Eng C Methods 2011;17:961-972.

21. Silva-Correia J, Miranda-Gonçalves V, Salgado AJ, Sousa N, Oliveira JM, Reis RM, Reis RL. Angiogenic potential of gellan-gumbased hydrogels for application in nucleus pulposus regeneration: In vivo study. Tissue Eng A 2012;18:1203-1212.

22. Silva-Correia J, Oliveira JM, Caridade SG, Oliveira JT, Sousa RA, Mano JF, Reis RL. Gellan gum-based hydrogels for intervertebral disc tissue-engineering applications. J Tissue Eng Regen Med 2011;5:e97-e107.

23. Silva-Correia J, Oliveira JM, Oliveira JT, Sousa RA, Reis RL Photo-crosslinked Gellan gum-based hydrogels: Methods and uses thereof. WO2011/119059, Priority date: 10503026032010 PT.

24. Holmes $\mathrm{MH}, \mathrm{Mow}$ VC. The nonlinear characteristics of soft gels and hydrated connective tissues in ultrafiltration. J Biomech 1990; 23:1145-1156.

25. Ateshian GA, Warden WH, Kim JJ, Grelsamer RP, Mow VC. Finite deformation biphasic material properties of bovine articular cartilage from confined compression experiments. J Biomech 1997;30: 1157-1164.

26. Iatridis JC, Setton LA, Foster RJ, Rawlins BA, Weidenbaum M, Mow VC. Degeneration affects the anisotropic and nonlinear behaviors of human anulus fibrosus in compression. J Biomech 1998;31:535-544.

27. Périé D, Korda D, latridis JC. Confined compression experiments on bovine nucleus pulposus and annulus fibrosus: Sensitivity of the experiment in the determination of compressive modulus and hydraulic permeability. J Biomech 2005;38:2164-2171.

28. Michalek AJ, Buckley MR, Bonassar LJ, Cohen I, latridis JC. The effects of needle puncture injury on microscale shear strain in the intervertebral disc annulus fibrosus. Spine J 2010;10:1098-1105.

29. latridis JC, Hecht AC. Commentary: Does needle injection cause disc degeneration? News in the continuing debate regarding pathophysiology associated with intradiscal injections. Spine J 2012; 12:336-338.

30. Singh K, Masuda K, An HS. Animal models for human disc degeneration. Spine J 2005;5:S267-S279.

31. Johannessen W, Elliott DM. Effects of degeneration on the biphasic material properties of human nucleus pulposus in confined compression. Spine (Phila Pa 1976) 2005;30:E724-E729.

32. Heneghan P, Riches PE. Determination of the strain-dependent hydraulic permeability of the compressed bovine nucleus pulposus. J Biomech 2008;41:903-906.

33. Martinez JB, Oloyede VOA, Broom ND. Biomechanics of loadbearing of the intervertebral disc: An experimental and finite element model. Med Eng Phys 1997;19:145-156.

34. Riches PE, Dhillon N, Lotz J, Woods AW, McNally DS. The internal mechanics of the intervertebral disc under cyclic loading. $J$ Biomech 2002;35:1263-1271.

35. Bron JL, Vonk LA, Smit TH, Koenderink GH. Engineering alginate for intervertebral disc repair. J Mech Behav Biomed Mater 2011:4: 1196-1205.

36. Bahney CS, Hsu C-W, Yoo JU, West JL, Johnstone B. A bioresponsive hydrogel tuned to chondrogenesis of human mesenchymal stem cells. FASEB J 2011;25:1486-1496.

37. Leahy JC, Hukins DWL. Viscoelastic properties of the nucleus pulposus of the intervertebral disk in compression. J Mater Sci Mater Med 2001;12:689-692.

38. Bowles RD, Gebhard HH, Härtl R, Bonassar LJ. Tissue-engineered intervertebral discs produce new matrix, maintain disc height, and restore biomechanical function to the rodent spine. Proc Nat Acad Sci USA 2011;108:13106-13111. 